AERODYNAMIC INTERFERENCE BETWEEN TWO DARRIEUS WIND TURBINES

P. R. Schatzle, P. C. Klimas, and H. R. Spahr

Prepered by Sandia Laboratories, Albuquarque, New Moxien 87185 and Livermore, Colifornia 94550 for the Unitod States Department of Eneriay under Contract DE-ACO4:780PCD789.

Printed Apri1 1981

When printing a copy of any digitized SAND Report, you are required to update the markings to current standards.

[1] Sandia National Laboratories energy reporf
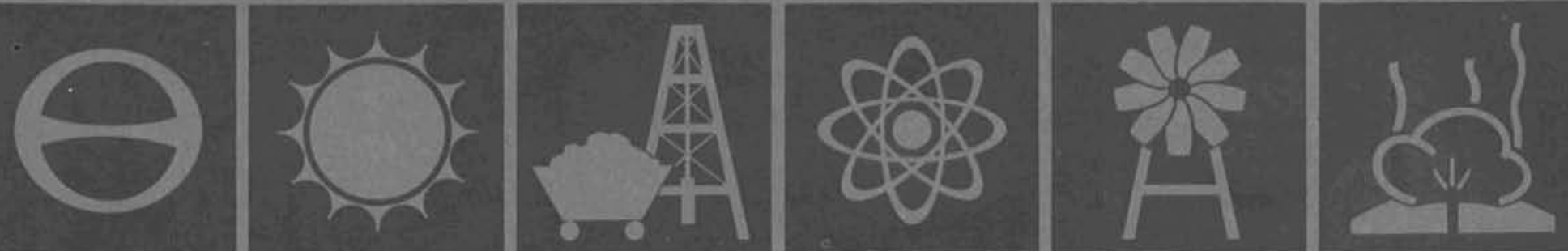
Issued by Sandia National Laboratories, operated for the United States Department of Energy by Sandia Corporation.

NOTICE: This report was prepared as an account of work sponsored by an agency of the United States Government. Neither the United States Government nor any agency thereof. nox any of their employees, nor any of their contractors, subcontractors, or their employees, makes any warranty, express or implied, ox assumes any legal liability or responsibility for the accuracy, completeness, or usefulness of any information, apparatus, product or process disciosed, or represents that its use would not infringe privately owned rights. Reference herein to any specific commercial product, process, or service imply its end, trademark, manufacturer, or otherwise, does not necessarily constitute or any agency thereof or, secommendalion, or lavoring by the United States Government. any agency thereor or any or their contractors or subcontractors. The views and opinion:

Government, any agency thereof or any of their contractors or subcontractors.
Ger State 


\section{Aerodynamic Interference Between Two Darrieus Wind Turbines}

P. R. Schatzle, P. C. Klimas, and H. R. Spahr

\section{Abstract}

The effect of aerodynamic interference on the performance of two curved bladed Darrieus-type vertical axis wind turbines has been calculated using a vortex/lifting line aerodynamic mode1. The turbines have a tower-to-tower separation distance of 1.5 turbine diameters, with the line of turbine centers varying with respect to the ambient wind direction. The effects of freestream turbulence were neqlected. For the cases examined, the calculations showed that the downwind turbine power decrement (1) was significant only when the line of turbine centers was coincident with the ambient wind direction, (2) increased with increasing tipspeed ratio, and (3) is due more to induced flow angularities downstream than to speed deficits near the downstream turbine. 


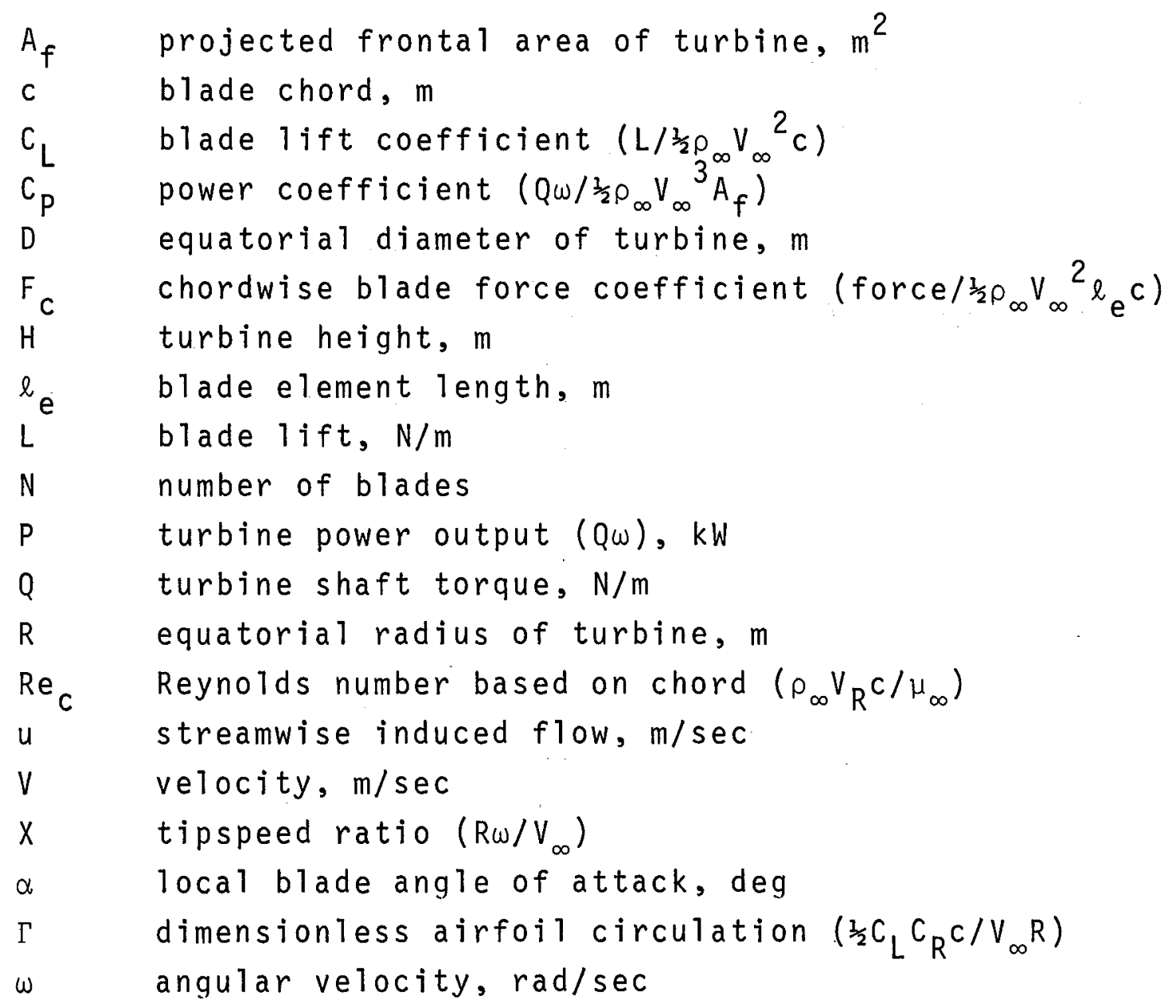

\section{Subscripts}

$\begin{array}{ll}R & \text { relative to local } \\ \infty & \text { freestream conditions }\end{array}$


Since its inception, the DOE Wind Energy Program has been largely concerned with the problems associated with individual wind turbines and systems. As the single turbine state-of-the-art has progressed, increasing attention is being given to the operation of turbines in multiple machine arrays. This attention is required because of the impact of turbine spacing on interconnect and land usage costs. Small separation distances work toward minimizing these as long as array members are not so close as to negatively interfere with each other aerodynamically. Sandia National Laboratories, with its Darrieus Wind Turbine Program, is interested in the problem of optimizing these separation distances.

Darrieus turbine aerodynamics is different from and somewhat more complicated than that of most horizontal axis wind turbines. Blades normally operate in both the linear and deep stall portions of the $C_{L} v s$ a curve. Although the wake may be periodic, it is unsteady and unsymmetrical. The flowfield downstream of an advancing blade differs from that downstream of a retreating blade and the blades do not operate independently of each other. There is always some degree of mutual interaction as blades cut wakes generated by those preceding. A mathematical representation which treats all of these effects is the vortex/lifting line model developed by Strickland, Webster, and Nguyen. ${ }^{1}$ In particular, it calculates a highly detailed wake. This wake is felt to be representative of actual turbine wakes within a few downwind diameters, i.e., before the non-included dissipative effects of atmospheric turbulence are no longer negligible. The model is viable and may be modified to simultaneously treat more than one turbine. As long as separation distances are small, the aerodynamic calculations may be considered realistic. 
This report describes a study of aerodynamic interference between two Darrieus turbines using a vortex/lifting line model without the effects of freestream turbulence.

Aerodynamic Model

Strickland, Webster, and Nguyen ${ }^{1}$ have developed a threedimensional model for use in predicting performance and detailed blade loads on a single Darrieus turbine, in which the blades and their wakes are replaced by an equivalent system of bound and free vortices. As the names imply, the bound vortices remain attached to the blades and rotate with them while the free vortices are shed from the blades into the ambient flow. The strength of the bound vortex (circulation) at any point on the blade is determined from the local blade lift using the Kutta-Joukowsky law, while the strengths of the free vortices are given in terms of the spatial and temporal variation of the circulation by Helmholtz's and Kelvin's theorems. Once the strengths of the vortex filaments are known, the BiotSavart law may be used to determine the velocity induced by the entire vortex system on any point. The total velocity seen by points on the blades is therefore the vector sum of the ambient, rotational, and induced velocities, while the free wake filaments experience only the ambient and induced velocities. Having obtained the velocity components on a given blade segment, the local angle of attack is computed and used to determine the aerodynamic forces acting on the segment by interpolation in the 1 ift and drag tables for the particular airfoil section used. Finally, the velocities of the wake filaments are integrated with respect to time to yield a developing wake geometry.

An interesting feature of this model is the fact that a detailed account of the rate at which energy is extracted from the wind is communicated downstream via the free vortex system. As more energy is removed from the wind, the amount of work done on the turbine increases, which means that the 
integral of the chordwise blade forces along the path of rotation increases. This implies an increase in the blade lift since it is the dominant component of the chordwise force. Accordingly, there is an increase in circulation on the blades and a corresponding increase in the strength of the shed vortices, resulting in higher induced velocities. A change in power output thus manifests itself in higher induced velocities downstream.

The presence of the free vortex system downwind of the turbine thus makes this model an attractive candidate for use in studying the aerodynamic interference on turbines in proximity. The VDART3 computer code developed by Strickland, et al, has been modified by the present authors in order to predict performance of an arbitrary number of Darrieus turbines. The turbines are required to be geometrically identical and to operate in phase but may be located wherever desired. A further refinement has been to interpolate on Reynolds number as well as angle of attack when computing blade element forces from the tabulated airfoil section data. In addition, an extensive graphics capability has been added in order to speed interpretation of results. This is described in more detail in the section Computer codes Used. The ability of the modified code (VDARTC) to accurately predict performance of a single turbine is demonstrated in Fig. 1 while the predicted wake geometry for the same turbine is given in Fig. 2 .

Computer Codes Used

The mathematical model of clustered three-dimensional vertical axis wind turbines, discussed in the previous section, was implemented in computer code VDARTC. VDARTC, while based on the VDART 3 computer code ${ }^{2}$, has been modified extensively by: 
1. Permitting the definition of the locations of the clustered turbines and computing the locations of each blade element for each turbine.

2. Properly allocating the array elements for computed variables to the appropriate blade elements for each wind turbine.

3. Adding a two-dimensional interpolation subroutine to include the effects of local blade element Reynolds number and the angle of attack on aerodynamic coefficients.

The program is now operational on the Sandia CDC Cyber 76 and 7600 computers using 111,216 (octa1) words of smal1 core memory and 155,030 (octal) words of large core memory in a batch mode.

The mathematical model of clustered wind turbines was also implemented in computer code WINMIL, an interactive graphics computer code being developed at Sandia to analyze two- and three-dimensional vertical axis wind turbines and giromills. The interactive feature, with human engineering, allows one to rapidly and easily make runs and the graphics output, described later, helps provide insight into the wake structure from the turbines and the variations of pertinent blade parameters with blade azimuthal position.

The graphics implementation of the clustered wind turbine model was based on the VDARTC computer code, with the simplification made to use a constant Reynolds number for all blade elements to minimize computer core requirements. To minimize core requirements, WINMIL consists of 29 overlays with 353 FORTRAN subroutines. WINMIL uses the Graphics Compatibility System (GCS) graphics language ${ }^{3-6}$. 
For short runs, WINMIL is used on a Sandia CDC $6600 \mathrm{com-}$ puter using Network Operating System (NOS) software in an interactive mode with Texas Instrument silent 700 series terminals, and Tektronix 4006, 4010, 4012, 4013, 4014, 4015, 4027 (color terminal), 4051 , and 4081 terminals. The computer code uses 107,603 (octal) core locations.

For longer runs, the interactive WINMIL program prepares the input data and then routes it to the Sandia cyber 76 or 7600 computers using SCOPE operating software. The batch version of the WINMIL program uses 120,102 (octal) words of smal1 core memory and 166,100 words of large core memory.

Output of the WINMIL program consists of:

1. Plots of the aerodynamic data being used for the airfoil and Reynolds number selected.

2. Plots of the vortex wakes shed by the equatorial element of each blade of each turbine.

3. Plots of airfoil angle of attack, airfoil nondimensional circulation, airfoil nondimensional normal force, and local nondimensional total velocity for each equatorial element of each blade of each turbine as a function of azimuthal position around the rotor revolution.

4. Tabulated average rotor power coefficients for each revolution.

This graphical output is easily available in a number of forms. These include hardcopy plots from the interactive terminals and black and white and color $35 \mathrm{~mm} \mathrm{slides}$ and black and white and color movies made by off-line computer output microfilm systems. Some of this graphical output has been used in the preparation of this report. 
Some of the runs required to generate the results for one orientation of the turbines and one tipspeed ratio required over two hours of CDC Cyber 76 or 7600 computer time. Obvious$1 y$, both Sandia National Laboratories and its contractors ${ }^{7}$ are pursuing ways to reduce the computer time required by these computer codes.

\section{Test Cases}

The large amount of CPU time required to run VDARTC prevents an extensive compilation of interference data in this report. Presented here is the predicted interference effect between two Darrieus wind turbines (Sandia $17-m$ configuration) with tower-to-tower spacing equal to three equatorial radii. The Sandia $17-m$ turbine is a $H / D=1$, troposkein approximation, blade planform machine having 2 blades of $0.61 \mathrm{~m}$ chord NACA 0015 profile. It develops $80 \mathrm{~kW}$ in a $19.7 \mathrm{~m} / \mathrm{sec}$ ambient wind at $1585 \mathrm{~m}$ altitude. The turbine solidity, $\sigma$, is 0.146 . Eight different orientations of the turbines were investigated as shown in Fig. 3, and the corresponding power coefficients obtained at a tipspeed ratio of 3 are tabulated in Table 1.

This tipspeed ratio was chosen because historically, the maximum value of shaft power is obtained near $x_{\infty}=3$. Of special interest is the case where the turbines are aligned in the streamwise direction (configuration A) since the largest power loss occurs there. For this orientation, a more complete power curve was generated and is shown in Fig. 4 compared to the predicted single turbine curve. The band on the downwind turbine prediction arises from the difficulty in obtaining numerical convergence at moderately high tipspeed ratios. Finally, Fig. 5 presents a typical sequence of plots which shows the development of the free vortex systems for both turbines $\left(x_{\infty}=4\right)$. 
TABLE 1

Predicted Power Coefficients for

Different Configurations, $X_{\infty}=3$

\begin{tabular}{ccc} 
Configuration & Turbine 1 & Turbine 2 \\
\hline A & .200 & .160 \\
B & .199 & .197 \\
C & .199 & .199 \\
D & .199 & .200 \\
E & .160 & .200 \\
F & .197 & .199 \\
G & .199 & .199 \\
H & .200 & .199 \\
Single Turbine & .199 & \\
\hline
\end{tabular}

Discussion of Results

The data summarized in Table 1 indicate that, for a towerto-tower spacing of three equatorial radii and $x_{\infty}=3$, the only orientation which produces a significant change in turbine power output is when the turbines are aligned in the streamwise direction. This is not surprising since the wake from the upwind turbine passes through the downwind turbine in this alignment, but not in the others. A more thorough investigation of the power curve (Fig. 4) for this alignment indicates that the power loss in the downwind turbine increases as the tipspeed ratio increases, at least over the range of speed presented.

The power loss at a given tipspeed ratio may be explained by considering the structure of the free vortex system associated with the upwind turbine. Figure 6 shows how the circulation on the equatorial blade element of the upwind turbine varies with angular position $(\theta)$ of the turbine (the sign convention for $\theta$ is shown in Fig. 7). Kelvin's theorem dictates that the strength of a shed vortex is equal in magnitude 
and opposite in sign to the temporal change in circulation of a blade element. It is evident that the circulation becomes increasingly negative over the left-hand side of the rotor $\left(\theta=90^{\circ}\right.$ to $\theta=270^{\circ}$, roughly), and positive over the righthand side $\left(\theta=270^{\circ}\right.$ back through $\theta=0^{\circ}$ to $\left.\theta=90^{\circ}\right)$. This means that, on the average, the vortices shed during the righthand half of the revolution will be negative sense (clockwise viewed from above) and those shed on the left-hand side will be positive sense (counterclockwise viewed from above). This situation is illustrated in Fig. 7 . It can be seen that a significant streamwise velocity is induced against the ambient flow by the free vortex system. The variation of the induced streamwise flow seen by a blade element as it rotates around the turbine is shown for both turbines in Fig. 8. (The data in Figs. 8-11 are for the equatorial blade segments, configuration $A, X_{\infty}=4$. Downwind 1 and 2 refer to different blades on the downwind turbine.) It might be expected that the difference in power output of the two turbines is due to smaller total velocity (greater induced flow) seen by the downwind turbine blades. Figure 9 shows, however, that although the variation of total velocity with $\Theta$ has a different character for the two turbines, the total velocities themselves (ambient plus induced plus rotation) are not significantly different. This is because the total velocity is dominated by the rotational component of velocity, at least at moderate tipspeed ratios. The major effect of the induced streamwise flow is to modify the local blade element angle of attack as shown in Fig. 10. This results in lower chordwise blade forces (Fig. 11) and, hence, lower torque and power. Therefore, as the tipspeed ratio of the upwind turbine increases, the blade circulation increases accompanied by an increase in the strength of the shed vortices, resulting in higher induced velocities, lower angles of attack downstream, and correspondingly, lower torque and power output. The trends in Fig. 4 thus appear reasonable. 
The mutual aerodynamic interference between two 17-m diameter Darrieus wind turbines with a tower-to-tower separation distance of 1.5 diameter has been calculated using a vortex/ lifting line model neglecting the effects of freestream turbulence. The calculations showed that, for the configurations examined, downstream turbine power reductions:

1. Are significant only when the two turbines were aligned with the ambient wind direction.

2. Increase with increasing tipspeed ratio for a fixed separation distance.

3. Are due more to changes in downstream flow angularities than velocity deficits.

The calculation of downstream turbine power decrements at separation distances greater than 1.5 diameter could be calculated if a suitable velocity deficit decay model were added to the basic vortex scheme. 


\section{References}

1. Strickland, J. H., Webster, B. T., and Nguyen, T., "A Vortex Model of the Darrieus Turbine: An Analytical and Experimental Study," American Society of Mechanical Engineers Paper No. 79-WA/FE-6, December 1979.

2. Strickland, J. H., Webster, B. T., and Nguyen, T., "A Vortex Model of the Darrieus Turbine" (A Final Report Submitted to Sandia National Laboratories on Sandia Contract No. 06-4178), Texas Tech University, Lubbock, Texas, January 1979 .

3. GCS, The Graphics Compatibility System, Primer, Sandia National Laboratories, Albuquerque, New Mexico.

4. GCS, The Graphics Compabitility System, Reference Manual, Sandia National Laboratories, Albuquerque, New Mexico.

5. Primer on Computer Graphics Programming (GCS), U.S. Army Corps of Engineers, Waterways Experiment Station, Vicksburg, Mississipi, 1978 .

6. Graphics Compatibility System (GCS) Programmer's Reference Manual, U.S. Army Corps of Engineers, Waterways Experiment Station, Vicksburg, Mississippi, 1978.

7. Strickland, J. H., "A Vortex Model of the Darrieus Turbine: An Analytical and Experimental Study" (A Progress Report Submitted to Sandia National Laboratories on Sandia Contract No. 13-5602, Period Covered: March 20, 1979 to August 20, 1979), Texas Tech University, Lubbock, Texas, September 1979 . 
FIGURE 1 Single Turbine Efficiency - Predicted vs Measured

FIGURE 2 Predicted Wake Geometry - Sandia 17-m Turbine, $X_{\infty}=4$ (Wake From Equatorial Segment of One Blade Only)

FIGURE 3 Orientation of Turbines in Test Case

FIGURE 4 Predicted Turbine Efficiencies, Configuration A

FIGURE 5 Predicted Wake Geometry, Configuration $A, X_{\infty}=4$ (Wake From Equatorial Segment of One Blade Only)

FIGURE 6 Azimuthal Variation of Circulation, Equatorial Segment of Upwind Turbine, $x_{\infty}=4$

FIGURE 7 Streamwise Flow Induced by Vortex system

FIGURE 8 Azimuthal Variation of Induced Streamwise Flow, $x_{\infty}=4$

FIGURE 9 Azimuthal Variation of Total Velocity, Equatorial Segments, $X_{\infty}=4$

FIGURE 10 Azimuthal Variation Angle of Attack, Equatorial Segments, $x_{\infty}=4$

FIGURE 11 Azimuthal Variation of Chordwise Blade Force, Equatorial Segments, $X_{\infty}=4$ 


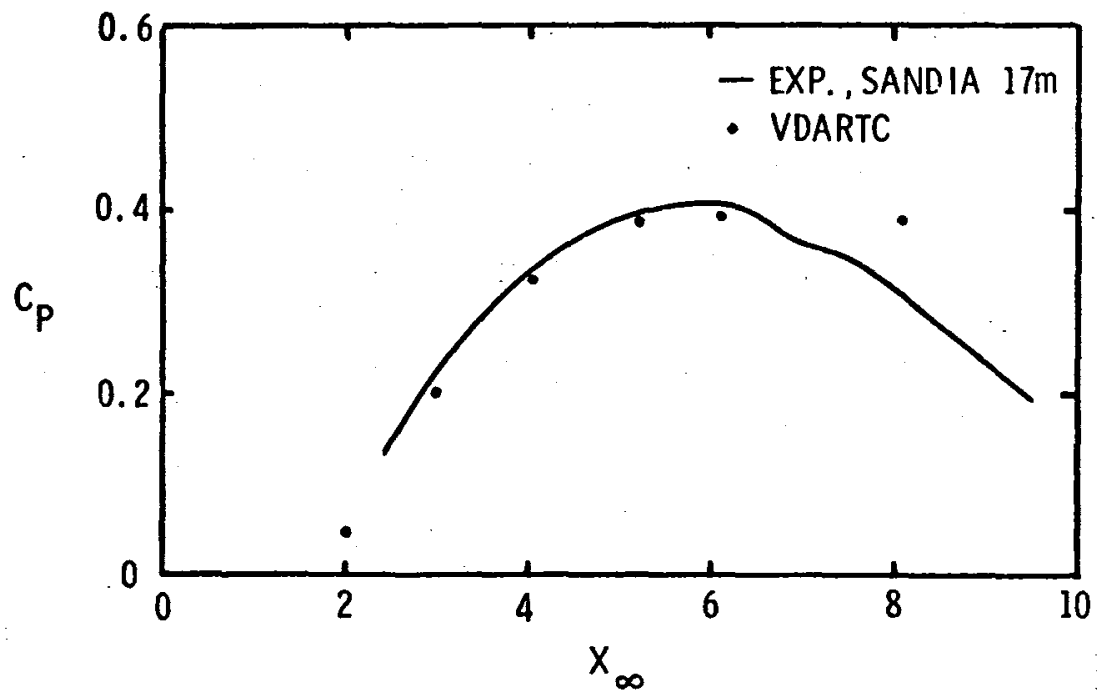

FIGURE 1

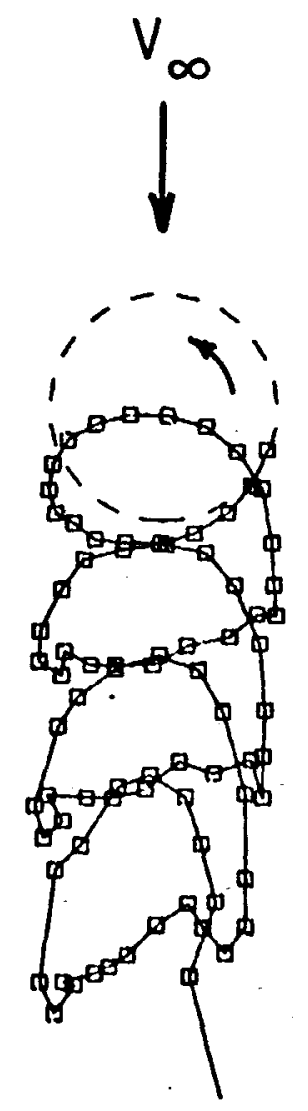

FIGURE 2 


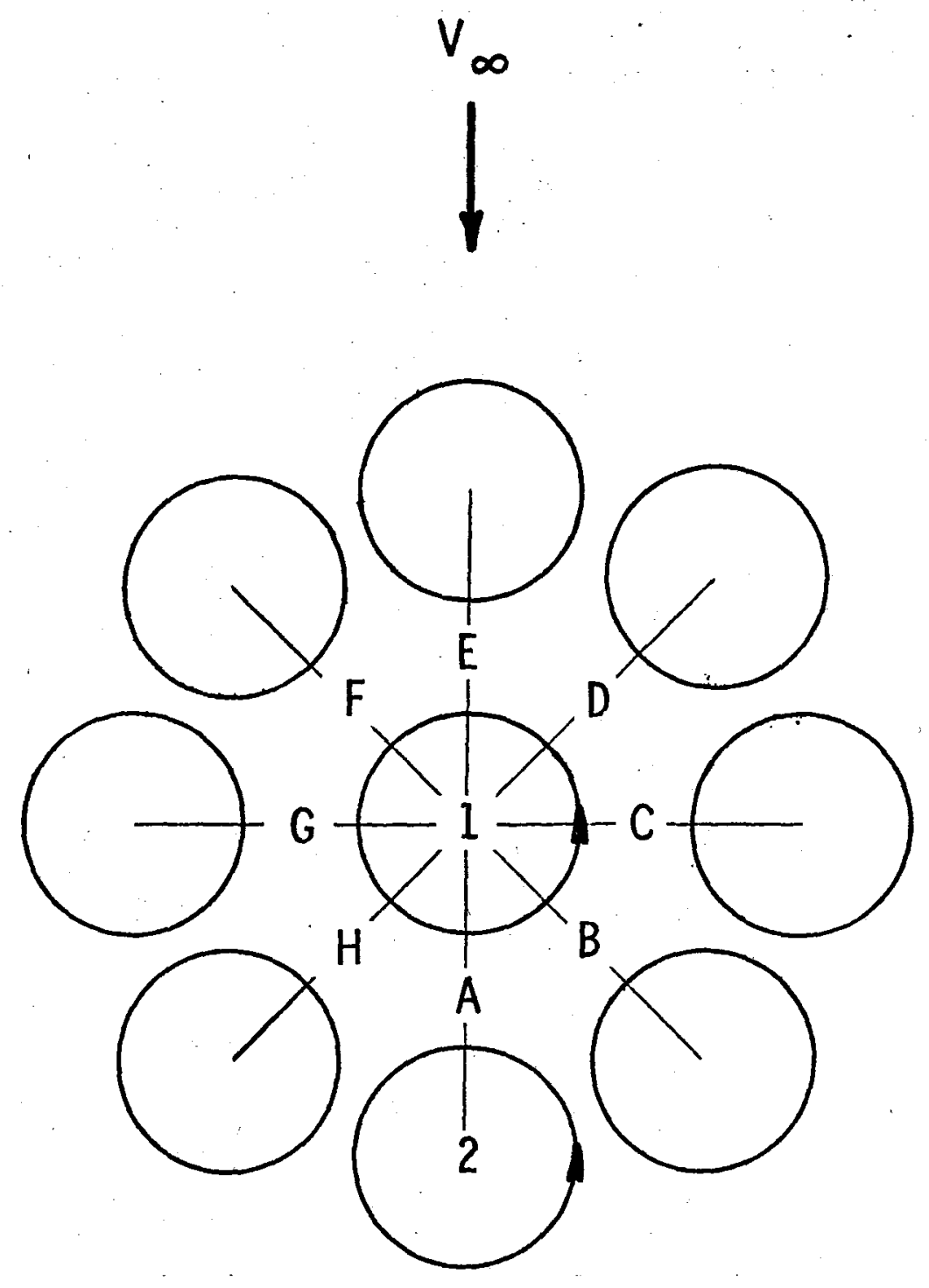

FIGURE 3 


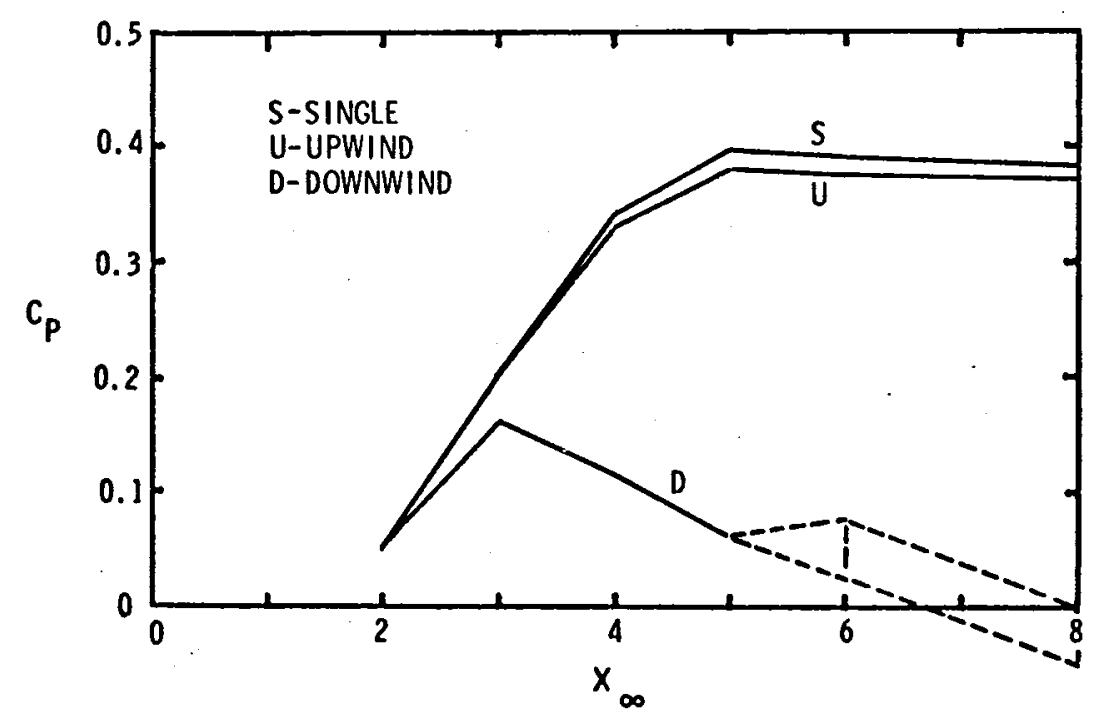

FIGURE 4

REV I

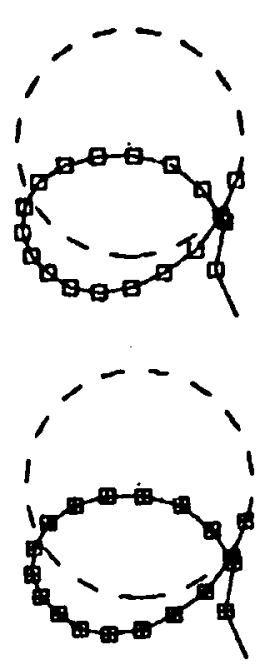

REV 2

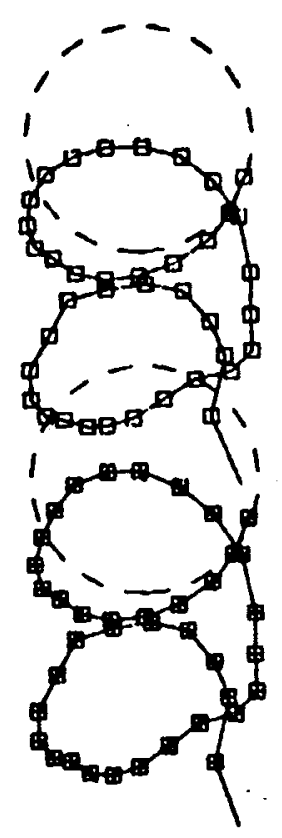

REV 3

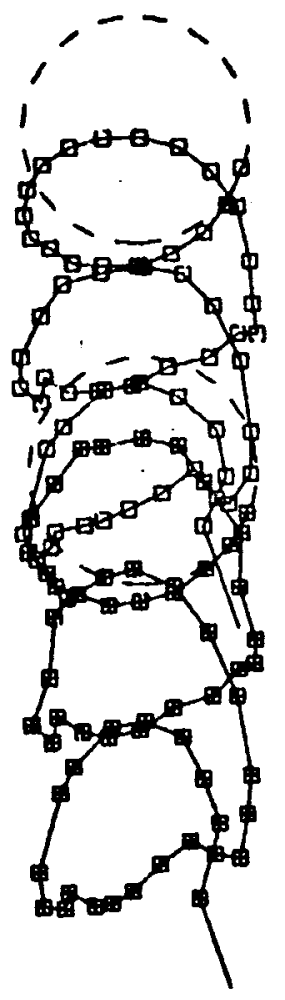

FIGURE 5 


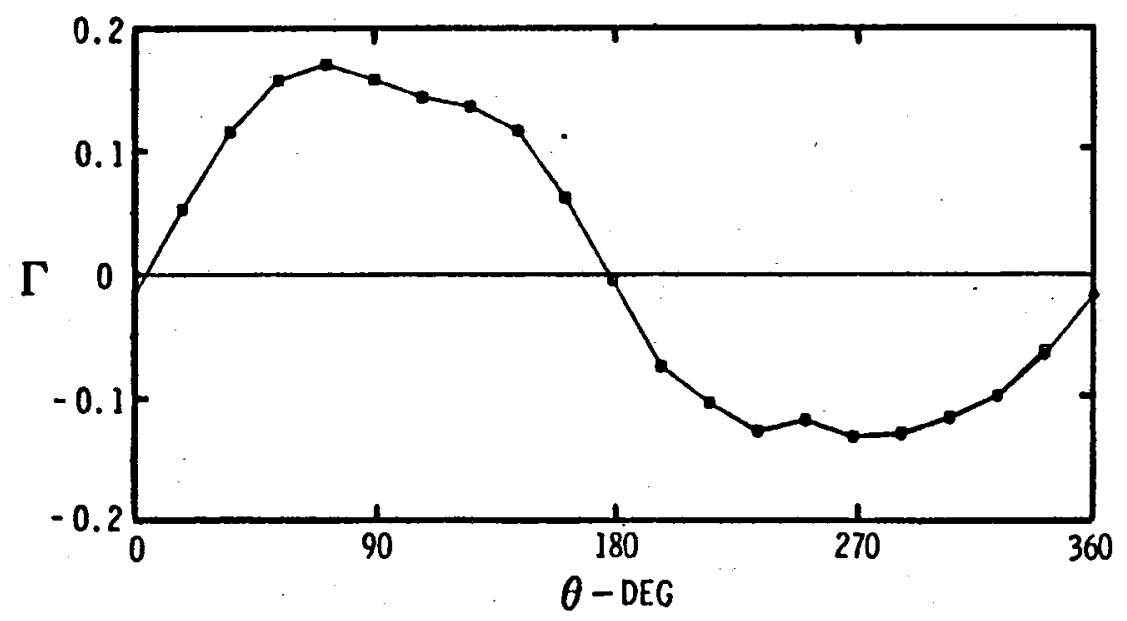

FIGURE 6

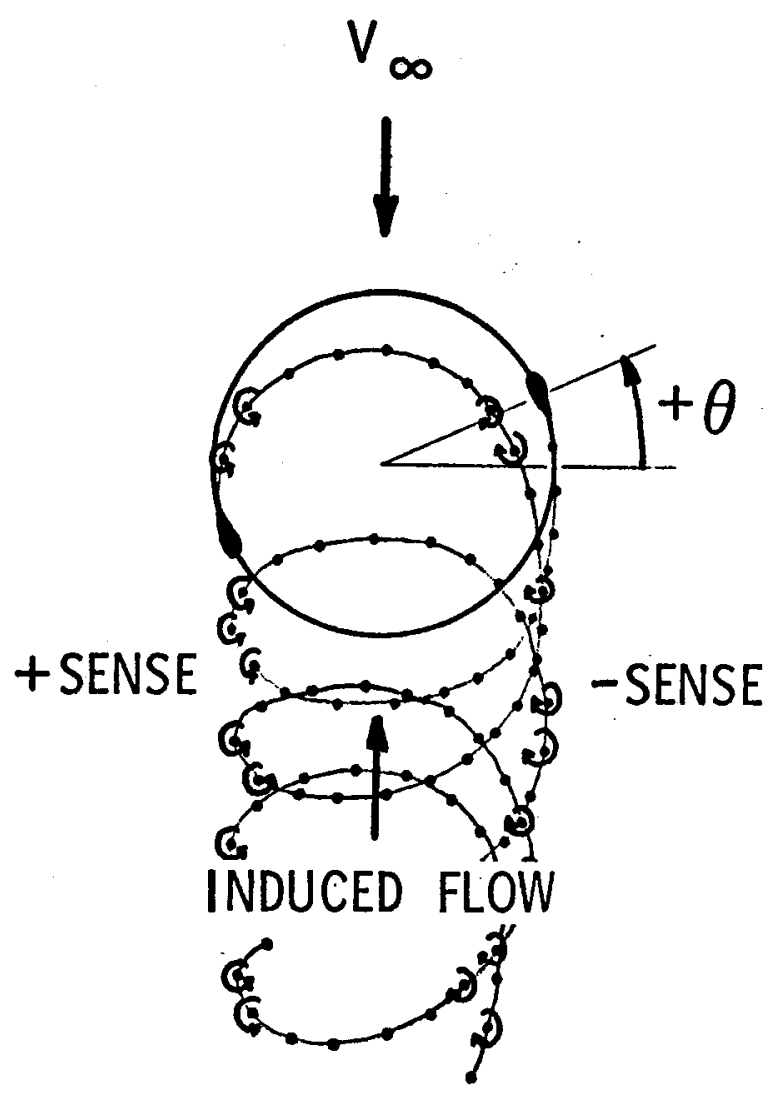

FIGURE 7 


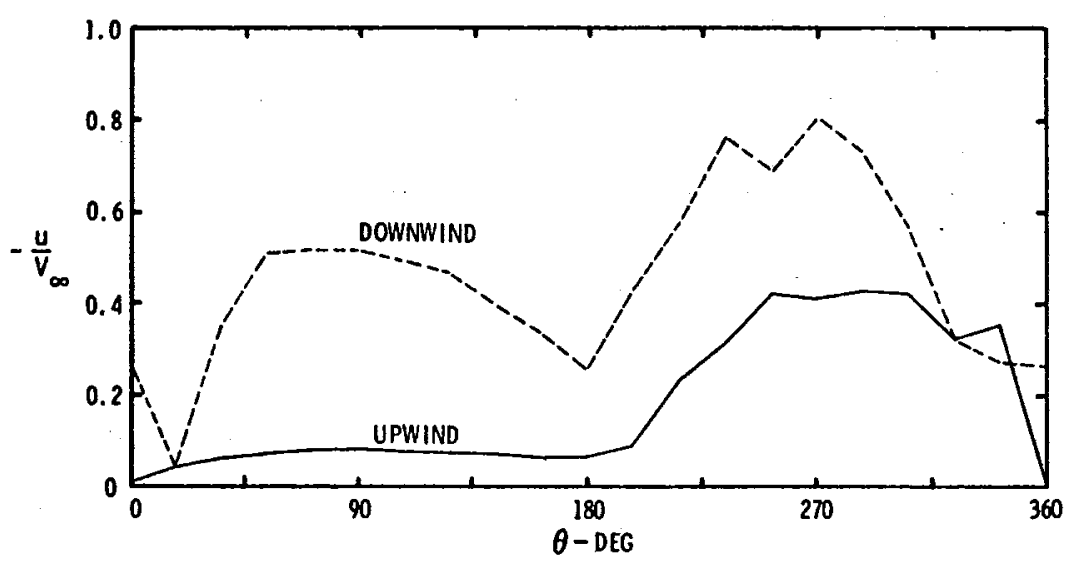

FIGURE 8

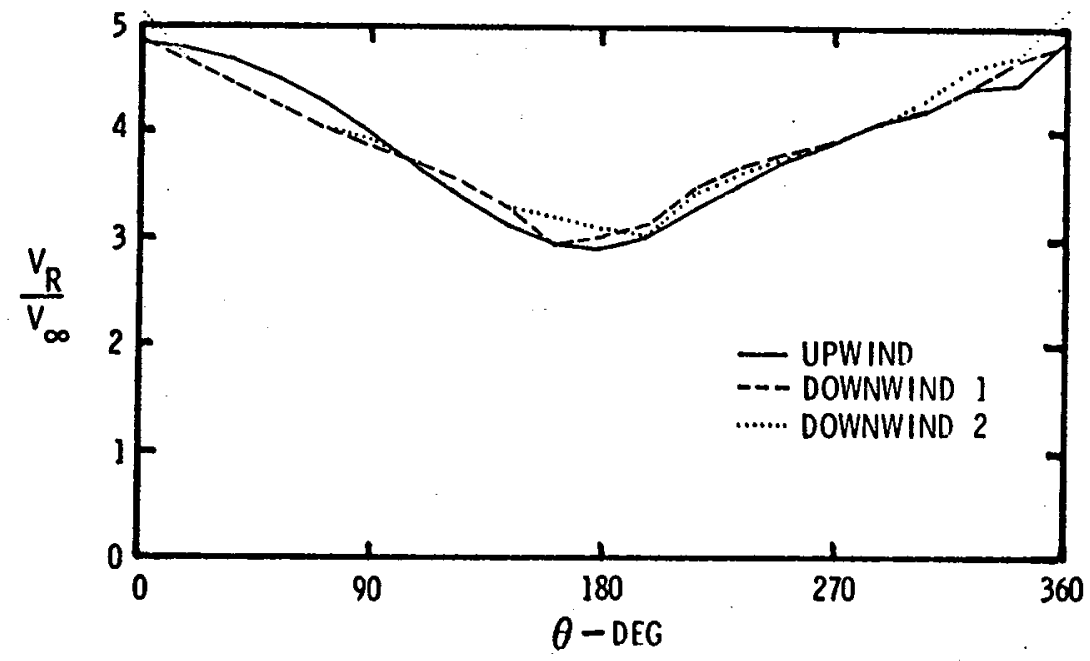

FIGURE 9 


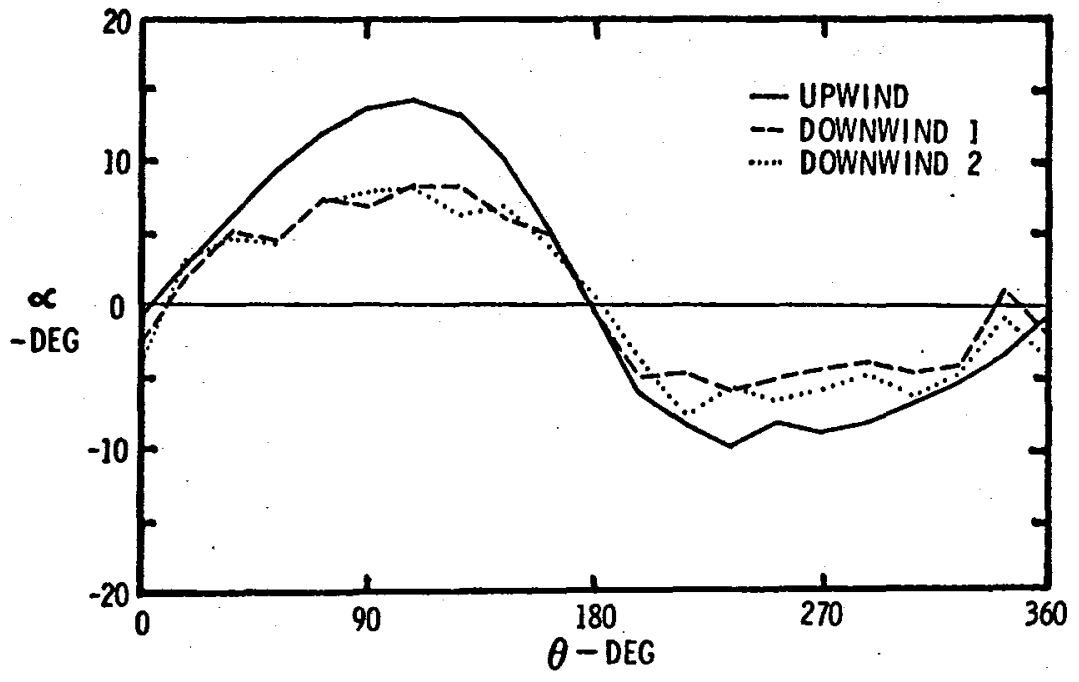

FIGURE 10

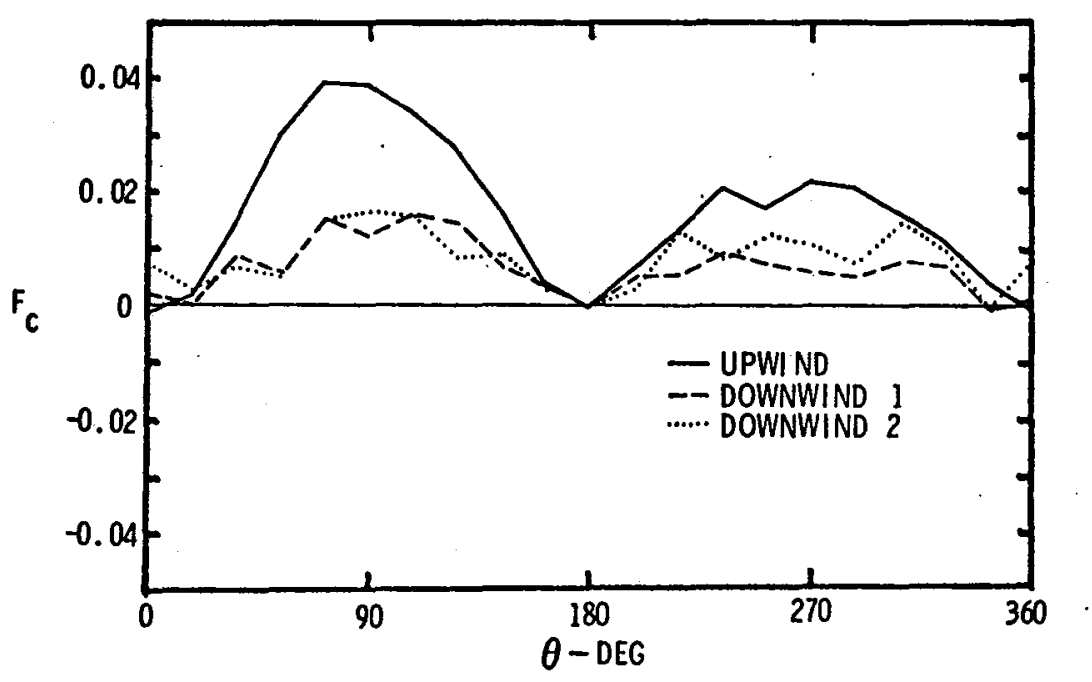

FIGURE 11 
DISTRIBUTION :

TID-4500-R6 UC-60 (283)

Aero Engineering Department (2)

Wichita State University

Wichita, KS 67208

Attn: M. Snyder

W. Wentz

R. E. Akins, Assistant Frofessor

Department of Engineering Science and Mechanics

Virginia Polytechnic Institute and state University

Blacksburg, VA 24060

Alcoa Laboratories (5)

Alcoa Technical Center

Aluminum Company of America

Alcoa Center, FA. 15069

Attn: D. K. Ai

A. G. Craig

J. T. Huang

J. R. Jombock

P. N. Vosburgh

Mr. Robert B. Allen

General Manager

Dynergy Corporation

P.O. Box 428

1269 Union Avenue

Laconia, $\mathrm{NH} 03246$

American wind Energy Association

1609 Connecticut Avenue NW

Washington, DC 20009

E. E. Anderson

South Dakota School of Mines

and Technology

Department of Mechanical Engineering

Rapid City, SD 57701

Scott Anderson

318 Millis Hall

University of Vermont

Burlington, VT 05405

G. T. Ankrum

DOE/Office of Commercialization

20 Massachusetts Avenue NW

Mail Station $2221 \mathrm{C}$

washington, DC 20585 


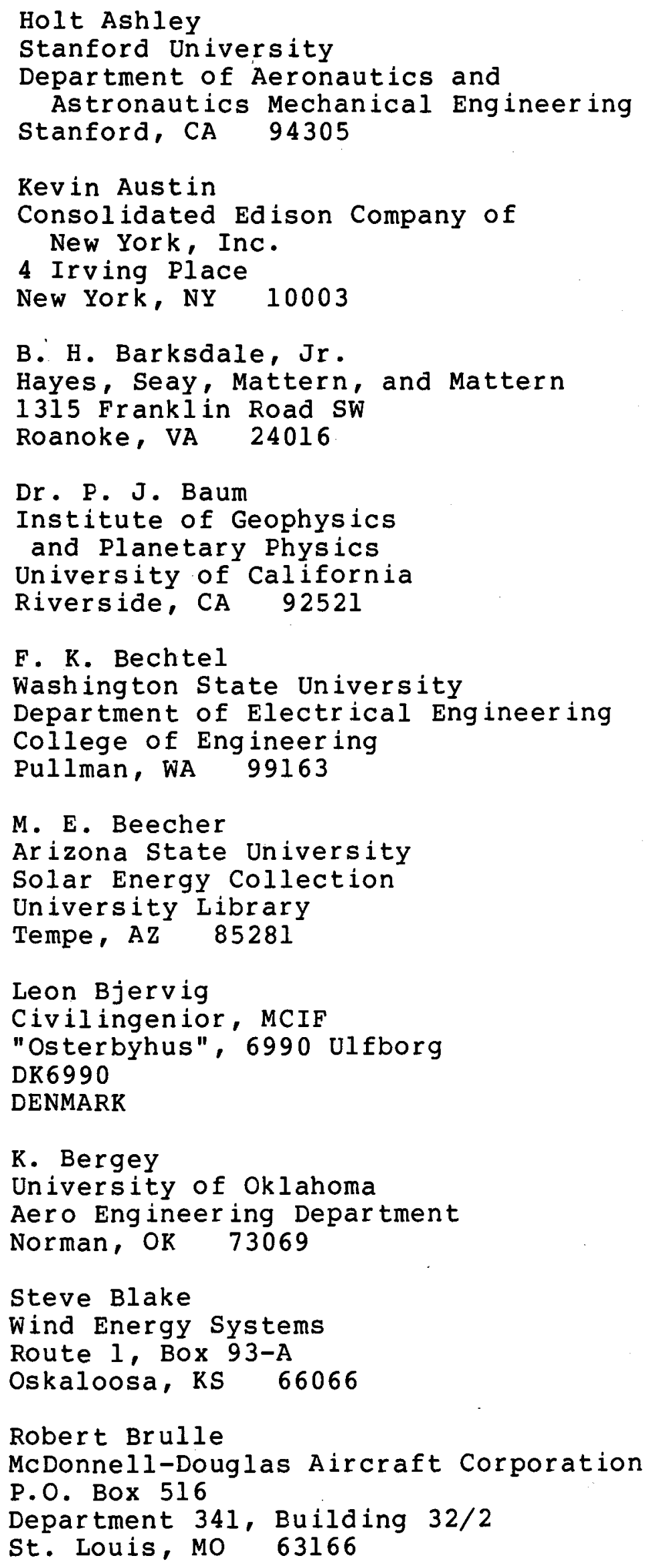




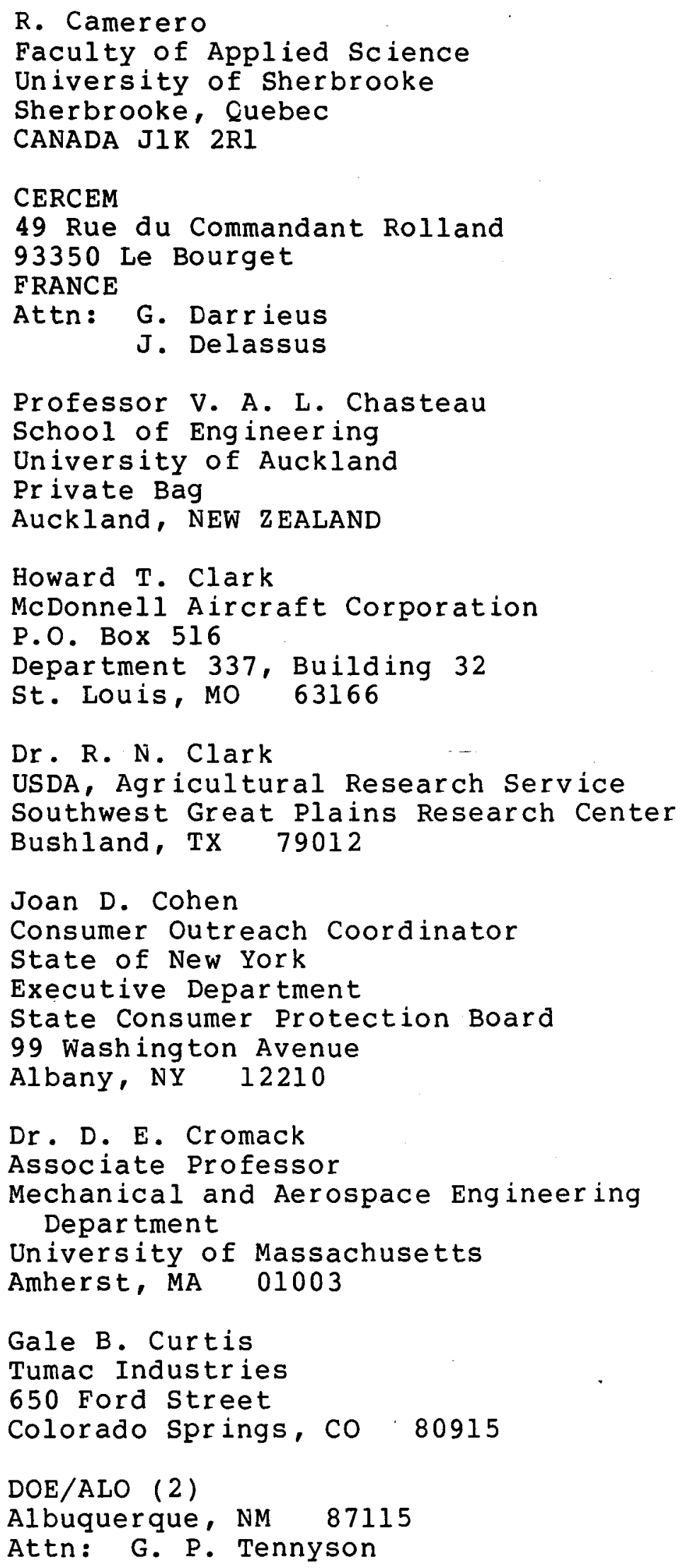




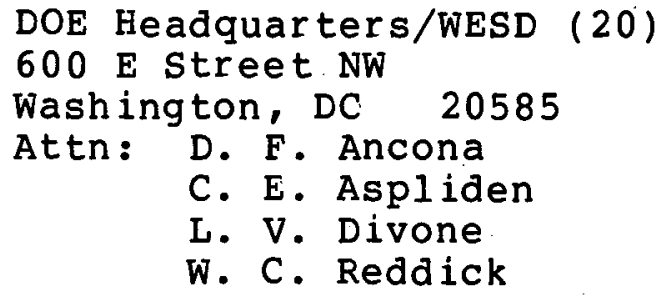

C. W. Dodd

School of Engineering

Southern Illinois University

Carbondale, IL 62901

D. D. Doerr

Kaiser Aluminum and Chemical Sales, Inc. 6177 Sunol Blvd.

P.O. Box 877

Pleasonton, CA 94566

Dominion Aluminum Fabricating Ltd. (2)

3570 Hawkestone Road

Mississauga, Ontario

CANADA L5C 2 U8

Attn: L. Schienbein

C. Wood

D. P. Dougan

Hamilton Standard

1730 NASA Boulevard

Room 207

Houston, TX 77058

J. B. Dragt

Nederlands Energy Research Foundation (E.C.N.)

Physics Department

Westerduinweg 3 Patten (nh)

THE . NETHERLANDS

C. E. Elderkin

Battelle-Pacific Northwest Laboratory

P.O. Box 999

Richland, WA 99352

Frank R. Eldridge, Jr.

The Mitre Corporation

1820 Dolley Madison Blvd.

McLean, VA 22102

Electric Power Research Institute

3412 Hillview Avenue

Palo Alto, CA 94304

Attn: E. Demeo 
Richard G. Ferreira, Chief

The Resources Agency

Department of water Resources

Energy Division

14169 th Street

P.O. Box 388

Sacremento, CA 95802

D. R. Finley

New England Geosystems

P.O. Box 128

East Derry, NH 03041

James D. Fock, Jr.

Department of Aerospace Engineering Sciences

University of Colorado

Boulder, CO 80309

Dr. Lawrence C. Frederick

Public Service Company of New Hampshire $1000 \mathrm{Elm}$ street

Manchester, $\mathrm{NH} \quad 03105$

H. Gerardin

Mechanical Engineering Department

Faculty of Sciences and Engineering

Universite Laval-Quebec

CANADA GIK 7P4

E. Gilmore

Amarillo College

Amarillo, TX 79100

Paul Gipe

Wind Power Digest

P.O. Box 539

Harrisburg, PA 17108

Roger T. Griffiths

University College of Swansea

Department of Mechanical Engineering

Singleton Park

Swansea SA2 8 PP

UNITED KINGDOM

Richard Haddad

101 Arizona

P.O. Box 530

El Paso, TX 79944

A. A. Hagman

Kaiser Aluminum and Chemical Sales, Inc.

14200 Cottage Grove Avenue

Dolton, IL 60419 


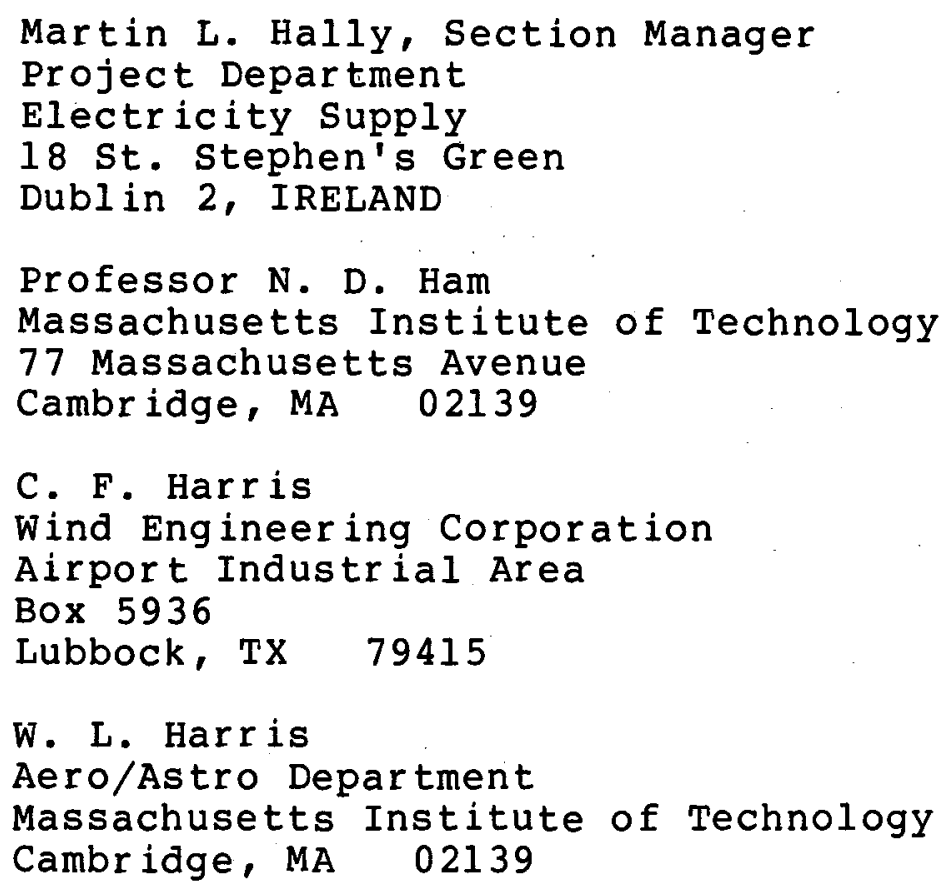

Helion

P.O. Box 4301

Sylmar, CA 91342

Don Hinrichsen

Associate Editor

AMBIO

KVA

Fack, S-10405

Stockholm

SWEDEN

Sven Hugosson

Box 21048

S. 10031 stockholm 21

SWEDEN

O. Igra

Department of Mechanical Engineering Ben-Gurion University of the Negev

Beer-Sheva, ISRAEL

Indian Oil Corporation, Ltd. Marketing Division

254-C, Dr. Annie Besant Road

Prabhadevi, Bombay -400025

INDIA 


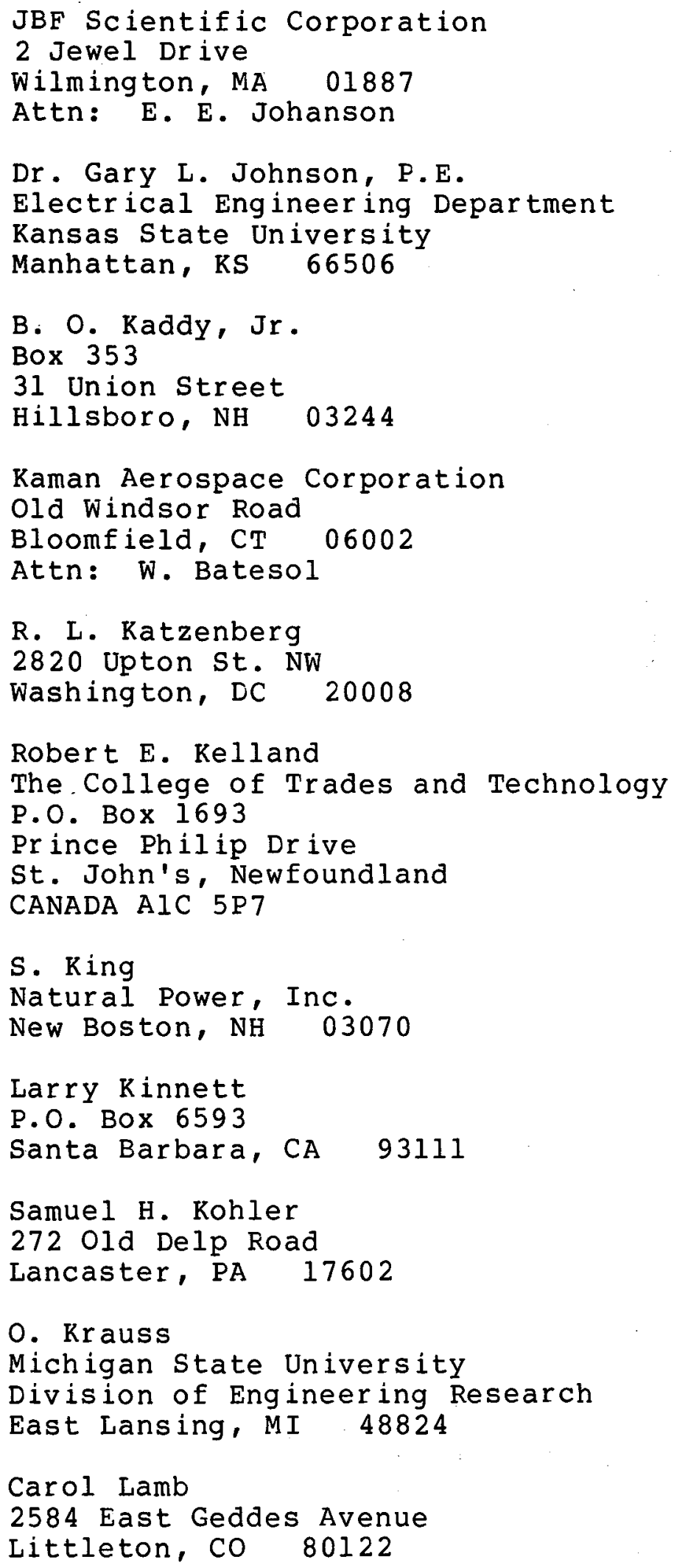




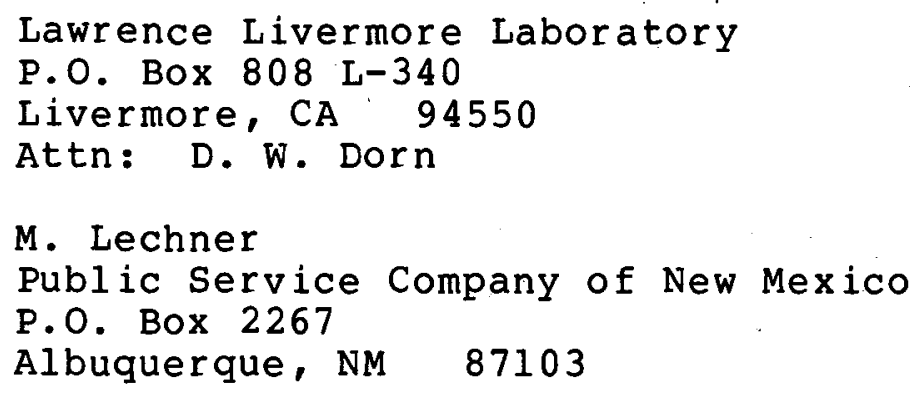

L. Liljidahl

Building 303

Agriculture Research Center USDA

Beltsville, MD 20705

P. B. S. Lissaman

Aeroenvironment, Inc.

660 South Arroyo Parkway

Pasadena, CA 91105

Olle Ljungstrom

FFA, The Aeronautical Research Institute Box 11021

S-16111 Bromma

SWEDEN

T. H. Logan

U.S. Turbine Corporation

Olde Courthouse Building

Canfield, $\mathrm{OH} \quad 44406$

$\mathrm{J}$. B . Longendyck

Siltex

7 Capitol Drive

Moonachie, NJ 07074 
Los Alamos Scientific Laboratories

P.O. Box 1663

Los Alamos, NM 87544

Attn: J. D. Balcomb Q-DO-T

Beatrice de Saint Louvent

Establissement d'Etudes et de Recherches Meteorologigues

77, Rue de Serves

92106 Boulogne-Billancourt Cedex

FRANCE

Ernel L. Luther

Senior Associate

PRC Energy Analysis Co.

7600 Old Springhouse Rd.

McLean, VA 22101

L. H. J. Maile

48 York Mills Rd.

willowdale, Ontar io

CANADA M2P $1 \mathrm{~B} 4$

E. L. Markowski

Motolola, Inc.

G.E.D.

Mail Drop 1429

8201 E. McDowell Rd.

P.O. Box 1417

Scottsdale, AZ 85252

Jacques R. Maroni

Ford Motor Company

Environmental Research and Energy Planning Director

Environmental and Safety Engineering Staff

The American Road

Dearborn, MI 48121

Frank Matanzo

Dardalen Associates

15110 Frederick Road

Woodbine, MD 21797

H. S. Matsuda, Manager

Composite Materials Laboratory

Pioneering R\&D Laboratories

Toray Industries, Inc.

Sonoyama, Otsu, Shiga

JAPAN 520 
J. R. McConnell

Tumac Industries, Inc.

650 Ford st.

Colorado Springs, CO 80915

James Meiggs

Kaman Sciences Corporation

P.O. Box 7463

Colorado Springs, CO 80933

R. N. Meroney

Colorado State University

Department of Civil Engineering

Fort Collins, CO 80521

G. N. Monsson

Department of Economic Planning and Development

Barrett Building

Cheyenne, WY 82002

NASA Lewis Research Center (4)

21000 Brookpark Road

Cleveland, OH 44135

Attn: J. Savino

R. L. Thomas

W. Robbins

K. Kaza

Anthony A. Nedd

The Power Company, Inc.

P.O. Box 221

Genesee Depot, WI 53217

V. Nelson

West Texas State University

Department of Physics

P.O. Box 248

Canyon, TX 79016

Leander Nichols

Natural Power, Inc.

New Boston, NH 03070

Ronald Nousa in

P.O. Box 111

Rome 1132

Los Angeles, CA 90051

Oklahoma state University (2)

Stillwater, OK 76074

Attn: W. L. Hughes

EE Department

D. K. McLaughl in

ME Department 
Oregon State University (2)

Corvallis, OR 97331

Attn: R. E. Wilson

ME Department

R. W. Thresher

ME Department

Pat F. O'Rourke

Precinct 4

County Commissioner

City-County Building

E1 Paso, TX 79901

H. H. Paalman

Dow Chemical USA

Research Center

2800 Mitchell Drive

Walnut Creek, CA 94598

Dr. Y. H. Pao, Chairman

Flow Industries, Inc.

2141468 th Ave. South

Kent, WA 98031

Ion Paraschivoiu

IREQ

1800 montee Ste-Julie

Varennes, Qeubec

CANADA JOL 2PO

R. A. Parmalee

Northwestern University

Department of Civil Engineering

Evanston, IL 60201

Helge Petersen

Riso National Laboratory

DK-4000 Roskilde

DENMARK

Wilson Prichett, III

National Rural Electric Cooperative

Association

1800 Massachusetts Avenue NW

Washington, DC 20036

Dr . Barry kawlings, Chief

Division of Mechanical Engineer ing

Commonwealth Scientific and Industrial

Research Organization

Graham Road, Highett

Victoria, 3190

AUSTRALIA 
Thomas $w$. Reddoch

Associate Professor

Department of Electrical Engineering

The University of Tennessee

Knoxville, TN 37916

Ray G. Richards

Atlantic Wind Test Site

P.O. Box 189

Tignish P.E.I.

COB 2BO CANADA

A. Robb

Memorial University of Newfoundland

Faculty of Engineer ing and Applied Sciences

St. John's Newfoundland

CANADA AlC 557

J. R. Rodriguez

Solarwind Energy Corporation

1163 Pomona Road

Unit $A$

Corona, CA 91720

Dr. -Ing. Hans Ruscheweyh

Institut fur Leichbau

Technische Hochschule Aachen

Wullnerstrasse 7

GERMANY

Gwen Schreiner

Librarian

National Atomic Museum

Albuquerque, NM 87185

Douglas B. Seely, P.E.

U.S. Department of Energy

P.O. Box 3621

102 NE Holladay

Portland, OR 97208

Arnan Seginer

Professor of Aerodynamics

Technion-Israel Institute of Technology

Department of Aeronautical

Eng ineer ing

Haifa, ISRAEL 
Dr. Horst Selzer

Dipl.-Phys.

Wehrtechnik und Energieforschung

ERNO-Raumfahrttechnik GmbH

Hunefeldstr . 1-5

Postfach 105909

2800 Bremen 1

GERMANY

H. Sevier

Rocket and Space Division

$\mathrm{Br}$ istol Aerospace Ltd.

P.O. Box 874

Winnipeg, Manitoba

CANADA R3C $2 S 4$

P. N. Shankar

Aerodynamics Division

National Aeronautical Laboratory

Bangalore 560017

INDIA

David Sharpe

Kingston Polytechnic

Canbury Park Road

Kingston, Surrey

UNITED KINGDOM

D. G. Shepherd

Cornell University

Sibley School of Mechanical and

Aerospace Engineering

Ithaca, NY 14853

Dr. Fred Smith

Mechanical Engineering Department Head

Colorado State University

Ft. Collins, CO 80521

Kent Smith

Instituto Technologico Costa Rica

Apartado 159 Cartago

COSTA RICA

Leo H. Soderholm

Iowa State University

Agricultural Engineer ing, Room 213

Ames, IA 50010

Bent Sorenson

Roskilde University Centery

Energy JGroup, Bldg. 17.2

IMFUFA

P.O. Box 260

DK-400 Roskilde

DENMARK 
Southwest Research Institute (2)

P.O. Drawer 28501

San Antonio, TX 78284

Attn: W. L. Donaldson, Senior Vice President

R. K. Swanson

Rick Stevenson

Route 2

Box 85

Springfield, MO 65802

Dale T. Stjernholm, P.E.

Mechanical Design Engineer

Morey/Stjernholm and Associates

1050 Magnolia Street

Colorado Springs, CO 80907

G. W. Stricker

130 Merchant St. \#1104

Honolulu, HI 96813

C. J. Swet

Route 4

Box 358

Mt. Airy, MD 21771

John Taylor

National Research Council

ASEB

2101 Constitution Avenue

Washington, DC 20418

R. J. Templ in (3)

Low Speed Aerodynamics Section

NRC-National Aeronautical Establishment

Ottawa 7, Ontario

CANADA K1A OR6

Texas Tech University (3)

P.O. Box 4389

Lubbock, TX 79409

Attn: K. C. Mehta, CE Department

J. Strickland, ME Department

J. Lawrence, ME Department

Fred Thompson

Atari, Inc.

155 Moffett Park Drive

Sunnyvale, CA 94086 
J. M. Turner, Group Leader

Terrestrial Energy Technology Program office

Energy Conversion Branch

Aerospace Power Division

Aero Propulsion Laboratory

Department of the Air Force

Air Force Wright Aeronautical Laboratories (AFSC)

Wright-Patterson Air Force Base, $\mathrm{OH} 45433$

United Engineers and Constructors, Inc.

Advanced Engineering Department

30 South 17 th Street

Philadelphia, PA 19101

Attn: A. J. Karalis

University of New Mexico (2)

New Mexico Engineering Research Institute

Campus, P.O. Box 25

Albuquerque, N.M.

87131

Attn: G. G. Leigh

University of New Mexico (2)

Albuquerque, NM 87106

Attn: K. T. Feldman

Energy Research Center

V. Sloglund

ME Department

Jan Vacek

Eolienne experimentale

C.P. 279, Cap-aux-Meules

Iles de la Madeleine, Quebec

CANADA

Irwin E. Vas

Solar Energy Research Institute

1617 Cole Blvd.

Golden, CO 80401

Otto de Vries

National Aerospace Laboratory

Anthony Fokkerweg 2

Amsterdam 1017

THE NETHERLANDS

R. Walters

West Virginia University

Department of Aero Engineering

1062 Kountz Avenue

Morgantown, WV 26505

E. J. Warchol

Bonneville Power Administration

P.O. Box 3621

Portland, OR 97225 
D. F. Warne, Manager

Energy and Power Systems

ERA Ltd.

Cleeve Rd.

Leatherhead

Surrey KT22 7SA

ENGLAND

G. R. Watson, Project Manager

The Energy Center

Pennine House

4 Osborne Terrace

Newcastle upon Tyne NE2 INE

UNITED KINGDOM

R. J. Watson

Watson Bowman Associates, Inc.

$1280 \mathrm{Niagara}$ St.

Buffalo, NY 14213

R. G. Watts

Tulane University

Department of Mechanical Engineering

New Orleans, LA 70018

W. G. Wells, P.E.

Associate Professor

Mechanical Engineer ing Department

Mississippi state University

Mississippi State, MS 39762

T. Wentink, Jr.

University of Alaska

Geophysical Institute

Fairbanks, AK 99701

West Texas state University

Government Depository Library

Number 613

Canyon, TX 79015

Wind Energy Report

Box 14

$102 \mathrm{~S}$. Village Ave.

Rockville Centre, NY 11571

Attn: Farrell Smith seiler

Wind Program Manager

Wisconsin Division of state Energy

8 th Floor

101 South Webster street

Madison, WI 53702 


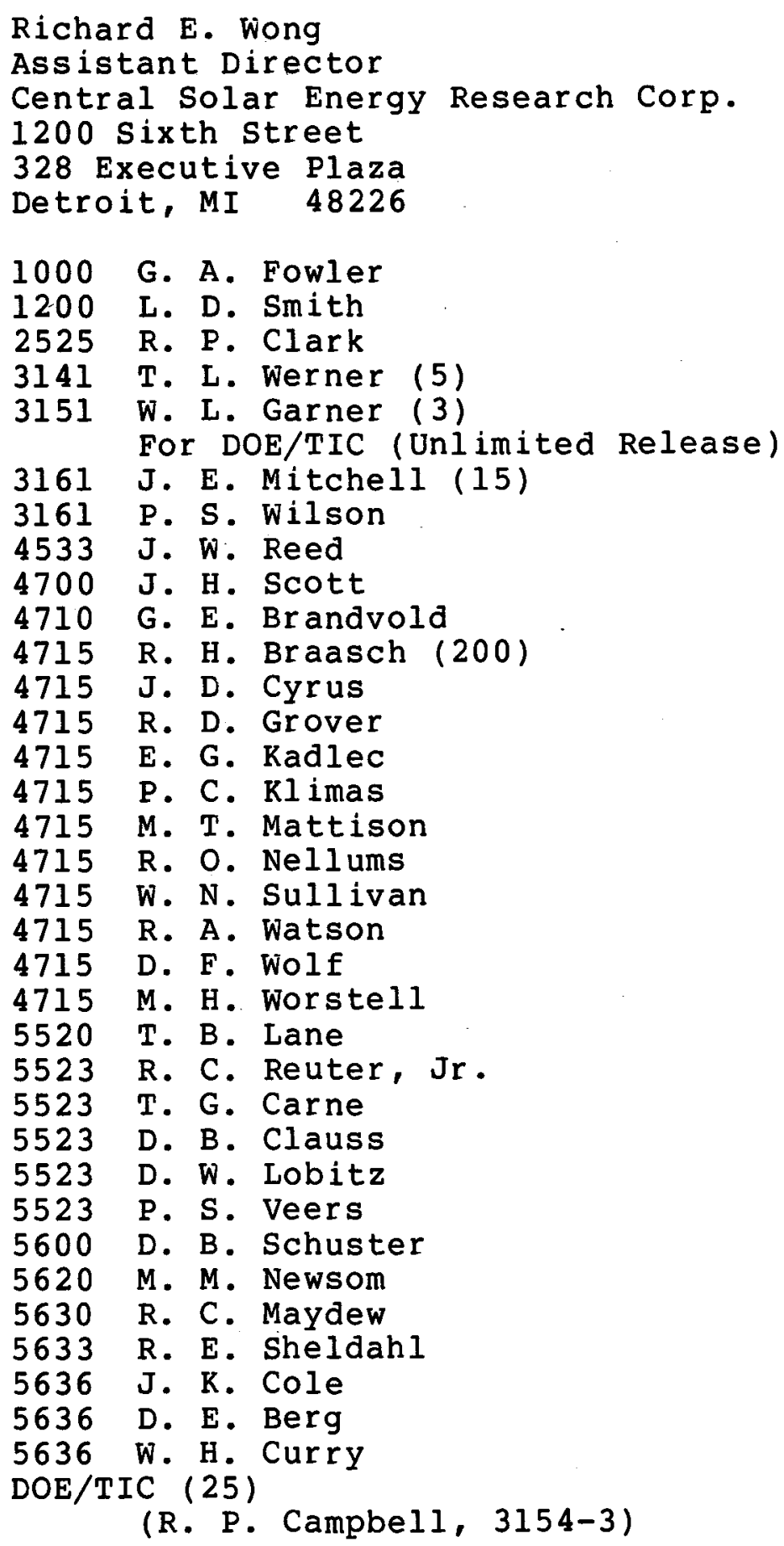

